Article

\title{
Short vs. Standard Length Cone Morse Connection Implants: An In Vitro Pilot Study in Low Density Polyurethane Foam
}

\author{
Luca Comuzzi ${ }^{1,+}$, Margherita Tumedei ${ }^{2, *,+}$, Adriano Piattelli ${ }^{2,3,4}$ and Giovanna Iezzi ${ }^{2}$ (i) \\ 1 Private practice, via Raffaello 36/a, 31020 San Vendemiano (TV), Italy; luca.comuzzi@gmail.com \\ 2 Department of Medical, Oral and Biotechnological Sciences, University “G. D'Annunzio" of Chieti-Pescara, \\ 66100 Chieti, Italy; apiattelli@unich.it (A.P.); g.iezzi@unich.it (G.I.) \\ 3 Catholic University of San Antonio de Murcia (UCAM), Av. de los Jerónimos, Guadalupe, \\ 13530107 Murcia, Spain \\ 4 Villaserena Foundation for Research, 65121 Città Sant'Angelo (Pescara), Italy \\ * Correspondence: margytumedei@yahoo.it; Tel.: +39-0871-3554083 \\ + These two Authors had an equal contribution to the study. LC for the execution of the experimental portion, \\ MT for data collection, data analysis, statistical evaluation, final editing of the manuscript.
}

Received: 9 October 2019; Accepted: 30 October 2019; Published: 1 November 2019

\begin{abstract}
The aim of the investigation was to evaluate the insertion torque, pull-out torque and implant stability quotient (ISQ) of short implants (SI) and standard length implants (ST) inserted into linearly elastic and constitutive isotropic symmetry polyurethane foam blocks. Short dental titanium implants with a Cone Morse connection and a conical shape (test implants: Test Implant A - diameter $5.5 \mathrm{~mm}$ and length $6 \mathrm{~mm}$ ) (Test Implant B-diameter $5.5 \mathrm{~mm}$ and length $5 \mathrm{~mm}$ ) were used for the present in vitro investigation. ST implants (4 $\mathrm{mm}$ diameter and $10 \mathrm{~mm}$ length), with a Cone Morse connection and a conical shape, were used as Control Implant A and as Control Implants B. These two latter implants had a different macro design. A total of 20 implants (5 Test A, 5 Test B, 5 Control A and 5 Control B) were used for the present research. The results were similar when comparing the Test A and Test B implants. The test implants had very good stability in polyurethane $14.88-29.76 \mathrm{kgm}^{3}$ density blocks. The insertion torque values were very high for both types of test implant (25-32 Ncm on $14.88 \mathrm{kgm}$ blocks, and up to $45 \mathrm{Ncm}$ in $29.76 \mathrm{kgm}^{3}$ blocks). The pull-out test values were very similar to the insertion torque values. The ISQ values were significantly high with $75-80$ in $14.88 \mathrm{kgm}^{3}$ blocks, and $78-83$ in $29.76 \mathrm{kgm}^{3}$ blocks. No differences were found in the values of the Control A and Control B implants. In both these implants, the insertion torque was quite low in the $14.88 \mathrm{kgm}^{3}$ blocks $\left(16-28 \mathrm{Ncm}\right.$ ). Better results were found in the $29.76 \mathrm{kgm}^{3}$ blocks. The pull-out values for these control implants were slightly lower than the insertion torque values. High ISQ values were found in both control implants (57-80). When comparing SI and ST implants, the SI had a similar if not better performance in low quality polyurethane foam blocks (14.88-29.76 kgm), corresponding to D3 and D4 bone.
\end{abstract}

Keywords: bone density; implant stability quotient; insertion torque; polyurethane foam blocks; pull-out torque; resonance frequency analysis; short implants; standard length implants

\section{Introduction}

Short implants (SI), defined in recent years as implants of less than $10 \mathrm{~mm}$ in length [1], seem to have some advantages in certain clinical situations, such as atrophy of the alveolar processes, poor bone quality, and pneumatization of the maxillary sinus [2]. SI are less invasive, simpler to use in the hands of the average clinician, and their surgery is shorter, with a lower morbidity, lower costs and 
lesser biological complications [1,3-7]. More recently, Ultrashort or Extra-short $(<6 \mathrm{~mm})$ implants have been proposed [8-11]. Alternatives to the use of SI are sinus augmentation procedures, the use of zygomatic implants, guided bone regeneration procedures, onlay grafts, inlay grafts, distraction osteogenesis, and lateralization of the inferior alveolar nerve $[4,12]$. Several recent systematic reviews, some of them with a metanalysis of the data, have shown:

no differences in the in the survival rate between SI and standard length implants (ST);

no differences in marginal bone loss (MBL);

lower biological complications in SI;

good primary stability in SI;

higher mechanical complications in SI [3,4,9,10,13-16].

Primary dental implant stability (PS), i.e., an absence of micromotion of the implant immediately after implant placement, has been reported to have an important role in implant osseointegration [17-19]. PS seemed to be closely correlated to bone quality and quantity, implant macrostructure, implant length and diameter, surgical technique, and the fitting of the implant into the site [17-21]. Bone density has been correlated to the amount of bone-to-implant contact (BIC) [19], and BIC to the PS [17]. Bone density has been measured with the use of different techniques: insertion torque (IT), removal torque (RT), and resonance frequency analysis (RFA), producing a value giving the implant stability quotient (ISQ) [22]. Polyurethane foam has been recognized as a standard material for testing instruments by the American Society for Testing and Materials (ASTM F-1839-08) ("Standard specification for Rigid Polyurethane Foam for Use as a Standard Material for Test Orthopaedic Devices for Instruments"). Polyurethane foam has been widely used as an alternative material in biomechanical tests evaluating, for example, dental implants. It presents consistent mechanical characteristics, has features similar to bone tissue, is very reliable and easy to use, requiring no special handling, and is characterized by linearly elastic and constitutive isotropic symmetry [22-24].

The scope of the present pilot study was to evaluate the insertion torque, pull-out torque and ISQ of SI and ST implants, positioned into polyurethane foam blocks.

\section{Materials and Methods}

\subsection{Dental Implants}

The short dental titanium implants with a Cone Morse connection and a conical shape (Implacil De Bortoli, Sao Paulo, Brasil) (Test Implants: Test Implant A-diameter $5.5 \mathrm{~mm}$ and length $6 \mathrm{~mm}$ ) (Test Implant B-diameter $5.5 \mathrm{~mm}$ and length $5 \mathrm{~mm}$ ) were used for the in vitro experimental study. Universal II (UN II) implants (4 mm diameter and $10 \mathrm{~mm}$ length), with a Cone Morse connection and a conical shape (Implacil De Bortoli, Sao Paulo, Brasil), were used as Control Implant A, and Universal III (UN III) implants, also with a Cone Morse connection and a conical shape (Implacil De Bortoli, Sao Paulo, Brasil), were used as Control Implants B. These two latter implants differed in their macro design. The UN III macro design differed from the UN II implants regarding its larger thread, the lack of double thread pitch, having a round apex not self-tapping, and in the chambers' patterns between the cutting surface of the threads.

\subsection{Study Design}

A total of 20 implants (5 Test A, 5 Test B, 5 Control A and 5 Control B) were used in the present investigation. The control implants were inserted following the protocol of the manufacturer: implant lance drill, $2 \mathrm{~mm}$ drill (1200 rpm) and $3.5 \mathrm{~mm}$ final drill ( $800 \mathrm{rpm}$ ) (Figures 1 and 2). The test implants were inserted following the protocol of the manufacturer: implant lance drill, $2 \mathrm{~mm}$ drill (1200 rpm), $3.5 \mathrm{~mm}$ conical drill for SI and $4.5 \mathrm{~mm}$ final conical drill for SI (800 rpm). 

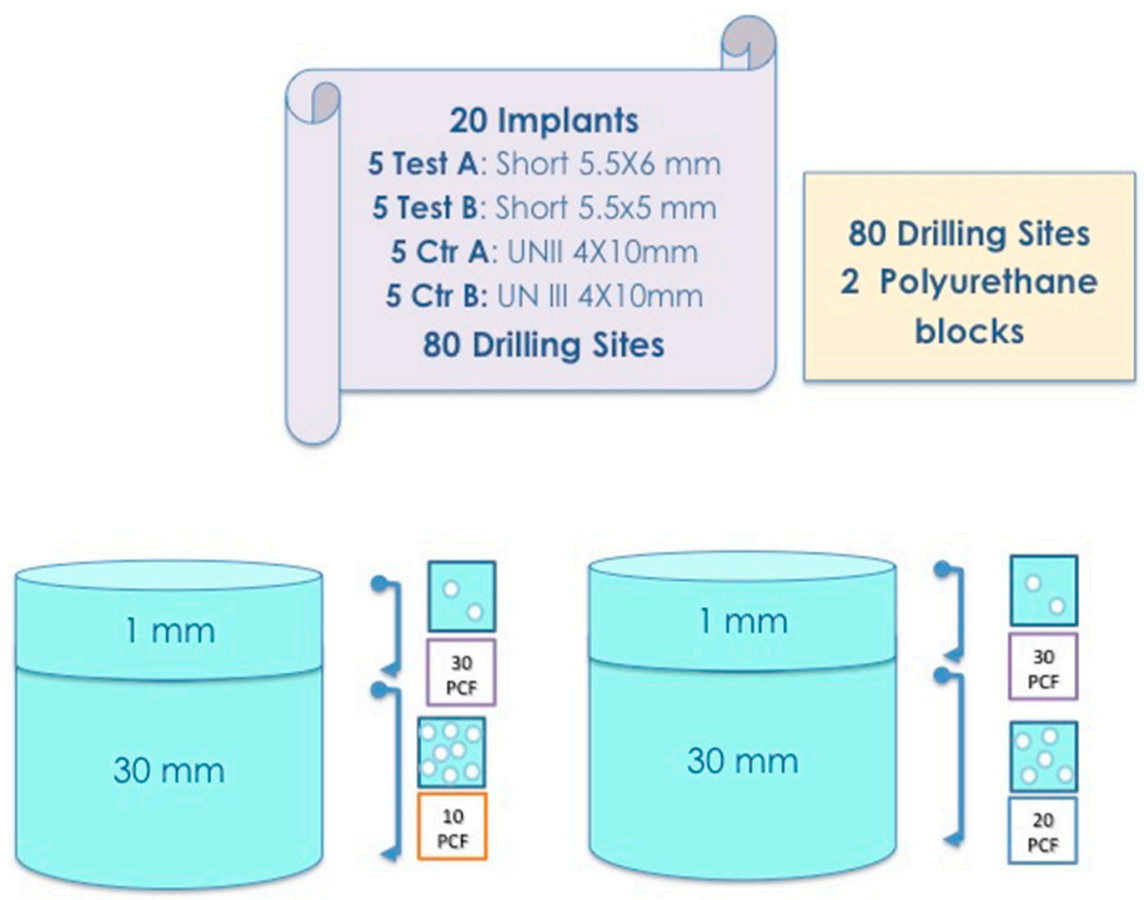

Figure 1. Study design and the experimental groups of the present in vitro investigation. PCF = pound per cubic foot.

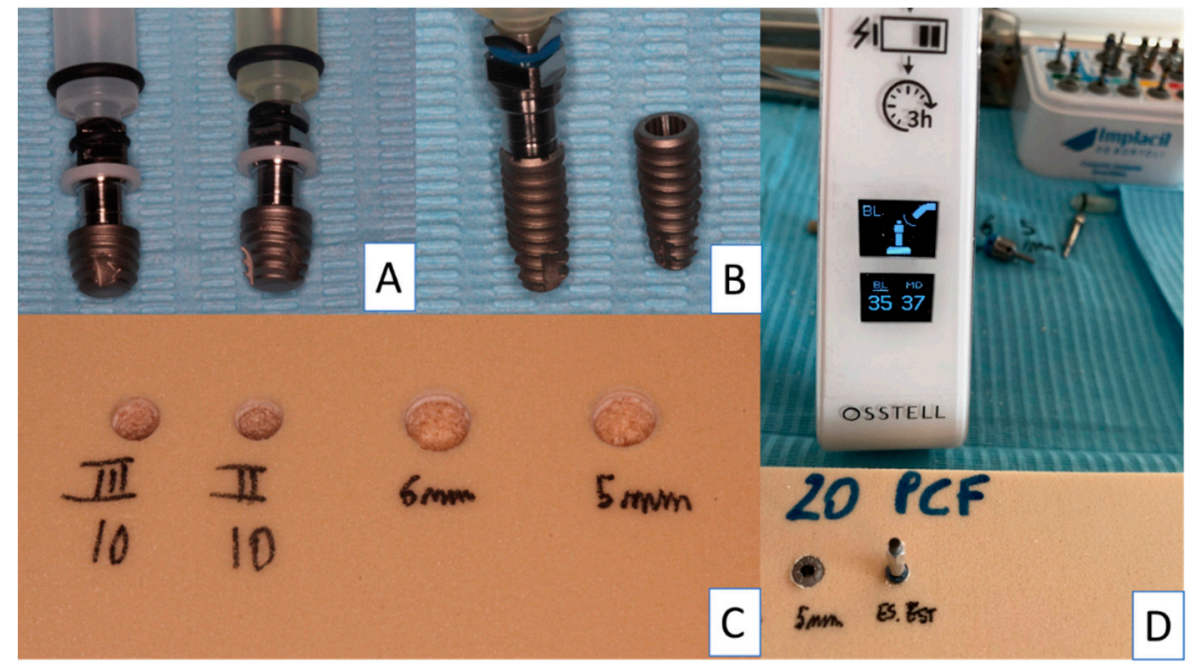

Figure 2. Sequence of the study investigation: (A) Test A and Test B; (B) Control A and Control B; (C) Polyurethane foam block after drilling; (D) implant stability quotient (ISQ) measurement device.

The insertion of the implants was made by the handpiece calibrated to $20 \mathrm{rpm}$ speed and a torque of $30 \mathrm{Ncm}$. The torque peaks were recorded by the software package (ImpDat Plus, East Lansing, Michigan) installed on a digital card. The insertion torque (IT, Ncm) peaks indicated the force of the maximum clockwise movement of the dental fixture positioned into the material. The research was performed by a single operator (LC), recording the fixture insertion and the pull-out torque peaks of the Test A, Test B, Control A and Control B Implants positioned into polyurethane foam blocks in different sizes and densities.

Different types of solid rigid polyurethane foam (SawBones H, Pacific Research Laboratories Inc, Vashon, Washington, USA) with homogeneous densities were selected for the present investigation. The polyurethane foam blocks presented a size of "120 $\mathrm{mm} \times 70 \mathrm{~mm} \times 31 \mathrm{~mm}$ ".

The block densities of polyurethane samples used in the present investigation were: $16.01 \mathrm{kgm}^{3}$ (10 PCF), similar to D3 bone quality, $32.02 \mathrm{kgm}^{3}$ (20 PCF), corresponding with and similar to D2 bone; 
moreover, a $1 \mathrm{~mm}$ sheet of polyurethane with a $48.03 \mathrm{kgm}^{3}$ (30 PCF) density, similar to D1 bone, was present to simulate a layer of cortical bone. Ten implant site perforations were performed for each type of implant (Test A, Test B, Control A and Control B) for both polyurethane densities (14.88-29.76 $\mathrm{kgm}^{3}$ ), for a total of 80 implant site preparations.

\subsection{Implant Drill}

Test $A$ and Test $B$ implants were inserted following a suggested drill protocol using a lance drill, then a $2 \mathrm{~mm}$ bur at $1200 \mathrm{rpm}$, then a $3.5 \mathrm{~mm}$ conical bur, and subsequently a $4.5 \mathrm{~mm}$ conical bur (both at $300 \mathrm{rpm}$ ) with the implant insertion at $20 \mathrm{Rpm}$. Control A and Control B Implants were inserted using a surgical lance drill, then a $2 \mathrm{~mm}$ bur, and subsequently a conical $3.5 \mathrm{~mm}$ bur at $800 \mathrm{Rpm}$ with the implant insertion at $20 \mathrm{rpm}$.

\subsection{Insertion Torque and Pull-Out Torque}

The comparative research evaluating the insertion torque and pull-out peaks was conducted using a calibrated torque ratchet (Implacil De Bortoli, Sao Paulo, Brasil) provided by a torque range of $5-80 \mathrm{~N} / \mathrm{cm}$. The final $1 \mathrm{~mm}$ insertion torque of the implants into the polyurethane blocks was evaluated using a calibrated torque ratchet (Implacil De Bortoli, Sao Paulo, Brasil). In the present investigation, the mechanical torque gauges were used to assess the insertion torque and the pull-out strength values.

\subsection{Resonance Frequency Evaluation}

After the fixture positioning, the primary stability was evaluated using Resonance Frequency analysis (RFA) values expressed in the implant stability quotient (ISQ) by a hand-screwed Smart-Pegs type 7 for test implants (Osstell Mentor Device, Integration Diagnostic AB, Savadelen, Sweden) (Figure 2). The ISQ values ranged from 0 to 100 (measured by a frequency in the range 3500-85,000 Hz), and was classified into Low (less than 60 ISQ), Medium (in the range 60-70 ISQ), and High stability rate (more than 70 ISQ) [25]. Moreover, RFA evaluation was repeated twice for each sample evaluated. The RFA evaluation was performed following two different orientations separated by a 90-degree angle, and the mean ISQ peaks were calculated.

\subsection{Statistical Analysis}

The Shapiro-Wilks test was performed to evaluate data normality. Moreover, the differences between the peaks of insertion torque, pull-out strength and the RFA of the study groups were evaluated using a two-way analysis of variance (ANOVA), followed by the Tukey post-hoc test. A $p$-value $<0.05$ was considered statistically significant. The research data and the statistical analysis were performed using the software package Excel (Microsoft Office, Redmond, USA) and GraphPad 6 (Prism, San Diego, USA).

\section{Results}

The results are similar when comparing the Test A and Test B implants. The test implants had very good stability in polyurethane $14.88-29.76 \mathrm{kgm}^{3}$ density blocks (Figures 3 and 4 ). 


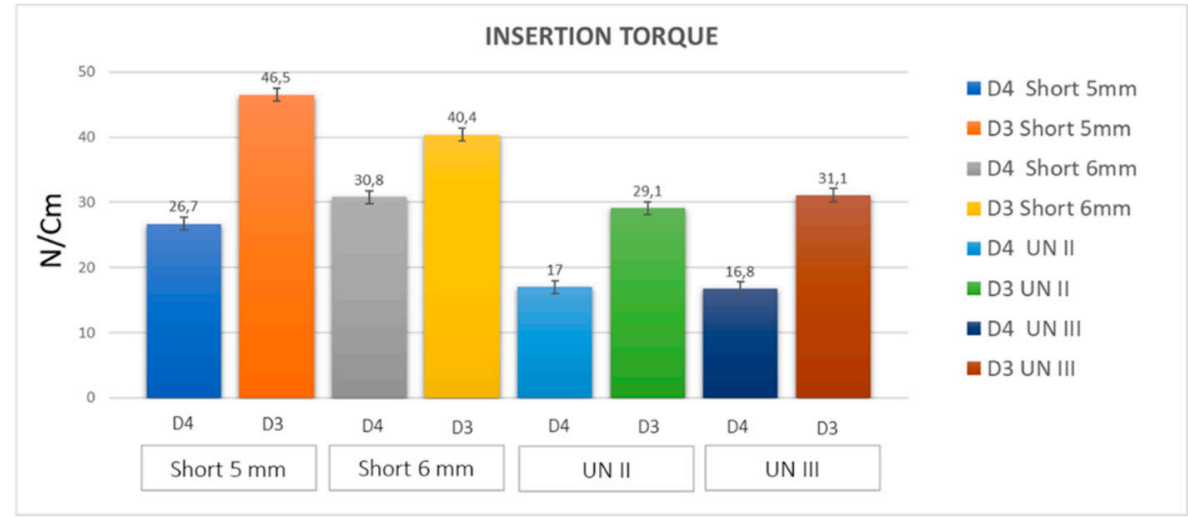

Figure 3. Insertion torque evaluation of the study groups: Test A, Test B. Control A and Control B.

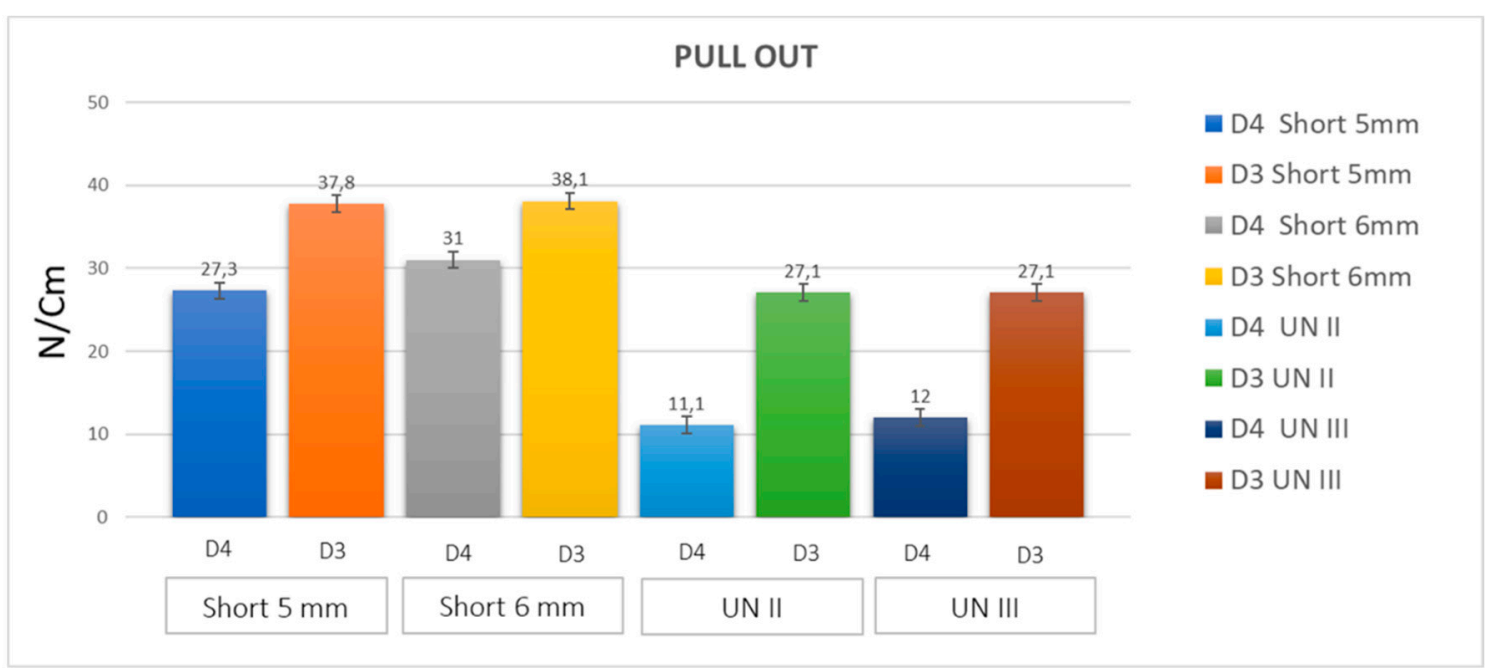

Figure 4. Pull-out outcome of the implant positioned into the polyurethane foam block: Test A, Test B.

Control A and Control B.

The insertion torque values were very high for both types of test implant (25-32 Ncm on $14.88 \mathrm{kgm}^{3}$ blocks, and up to $45 \mathrm{Ncm}$ in $29.76 \mathrm{kgm}^{3}$ blocks) (Figure 3; Tables 1 and 2).

The pull-out test values were very similar to the insertion torque values (Figure 4). The ISQ values were significantly high with $75-80$ in $14.88 \mathrm{kgm}^{3}$ blocks, and $78-83$ in $29.76 \mathrm{kgm}^{3}$ blocks (Tables 3 and 4 ).

Table 1. Summary of the insertion torque value for the implant positioned into polyurethane foam $\left(14.88-29.76 \mathrm{kgm}^{3}\right)$; Test A, Test B. Control A and Control B.

\begin{tabular}{ccccccccc}
\hline \multirow{2}{*}{$\begin{array}{c}\text { Insertion } \\
\text { Torque }\end{array}$} & $\begin{array}{c}\text { Short 5 } \\
\text { mm (A) }\end{array}$ & $\begin{array}{c}\text { Short 6 } \\
\text { mm (B) }\end{array}$ & $\begin{array}{c}\text { UN II } \\
\text { (C) }\end{array}$ & $\begin{array}{c}\text { UN III } \\
\text { (D) }\end{array}$ & $\begin{array}{c}\text { Short 5 } \\
\text { mm (E) }\end{array}$ & $\begin{array}{c}\text { Short 6 } \\
\text { mm (F) }\end{array}$ & $\begin{array}{c}\text { UN II } \\
\text { (G) }\end{array}$ & $\begin{array}{c}\text { UN III } \\
\text { (H) }\end{array}$ \\
\hline Mean & 26.7 & 30.8 & 17 & 16.8 & 46.5 & 40.4 & 29.1 & 31.1 \\
\hline $\begin{array}{c}\text { Std. } \\
\text { Deviation }\end{array}$ & \pm 1.059 & \pm 1.033 & \pm 0.942 & \pm 1.135 & \pm 1.269 & \pm 1.350 & \pm 0.994 & \pm 0.994 \\
\hline
\end{tabular}


Table 2. Insertion torque: ANOVA Bonferroni post-hoc comparison test $(\mathrm{CI}=$ Confidence Interval; Diff $=$ Difference) .

\begin{tabular}{ccc}
\hline Multiple Comparison Insertion Torque & $\mathbf{9 5 . 0 0 \%}$ CI of Diff, & Adjusted $p$ Value \\
\hline A-B & -5.577 to -2.623 & $<0.0001$ \\
\hline B-C & 12.32 to 15.28 & $<0.0001$ \\
\hline C-D & -1.277 to 1.677 & N.S.D. \\
\hline D-E & -31.18 to -28.22 & $<0.0001$ \\
\hline A-D & 8.423 to 11.38 & $<0.0001$ \\
\hline A-C & 8.223 to 11.18 & $<0.0001$ \\
\hline B-D & 12.52 to 15.48 & $<0.0001$ \\
\hline E-F & 4.623 to 7.577 & $<0.0001$ \\
\hline F-G & 9.823 to 12.78 & $<0.0001$ \\
\hline G-H & -3.477 to -0.5230 & 0.0006 \\
\hline E-H & 13.92 to 16.88 & $<0.0001$ \\
\hline F-H & 7.823 to 10.78 & $<0.0001$ \\
\hline E-G & 15.92 to 18.88 & $<0.0001$ \\
\hline
\end{tabular}

N.S.D. (no significant differences).

Table 3. Summary of the pull-out outcome of the implant positioned into polyurethane foam (14.88 D3 Density-29.76 kgm ${ }^{3}$ D3 Density); Test A, Test B. Control A and Control B.

\begin{tabular}{ccccccccc}
\hline & \multicolumn{4}{c}{ D4 Density } & \multicolumn{5}{c}{ D3 Density } \\
\cline { 2 - 9 } Pull Out & $\begin{array}{c}\text { Short 5 } \\
\text { mm (A) }\end{array}$ & $\begin{array}{c}\text { Short 6 } \\
\text { mm (B) }\end{array}$ & $\begin{array}{c}\text { UN II } \\
\text { (C) }\end{array}$ & $\begin{array}{c}\text { UN III } \\
\text { (D) }\end{array}$ & $\begin{array}{c}\text { Short 5 } \\
\text { mm (E) }\end{array}$ & $\begin{array}{c}\text { Short 6 } \\
\text { mm (F) }\end{array}$ & $\begin{array}{c}\text { UN II } \\
\text { (G) }\end{array}$ & $\begin{array}{c}\text { UN III } \\
\text { (H) }\end{array}$ \\
\hline Mean & 27.3 & 31 & 11.1 & 12 & 37.8 & 38.1 & 27.1 & 27.1 \\
\hline $\begin{array}{c}\text { Std. } \\
\text { Deviation }\end{array}$ & \pm 1.059 & \pm 1.054 & \pm 0.994 & \pm 1.247 & \pm 0.918 & \pm 0.875 & \pm 1.101 & \pm 1.287 \\
\hline
\end{tabular}

Table 4. Pull-out: ANOVA Bonferroni post-hoc comparison test $(\mathrm{CI}=$ Confidence Interval; Diff $=$ Difference) .

\begin{tabular}{ccc}
\hline Multiple Comparison Pull Out & $\mathbf{9 5 . 0 0 \%}$ CI of Diff, & Adjusted $\boldsymbol{p}$ Value \\
\hline A-B & -5.124 to -2.276 & $<0.0001$ \\
\hline B-C & 18.48 to 21.32 & $<0.0001$ \\
\hline C-D & -2.324 to 0.5237 & N.S.D. \\
\hline A-D & 13.88 to 16.72 & $<0.0001$ \\
\hline B-D & 17.58 to 20.42 & $<0.0001$ \\
\hline A-C & 14.78 to 17.62 & $<0.0001$ \\
\hline D-E & -27.24 to -24.36 & $<0.0001$ \\
\hline E-F & -1.724 to 1.124 & $>0.9999$ \\
\hline F-G & 9.576 to 12.42 & $<0.0001$ \\
\hline G-H & -1.424 to 1.424 & N.S.D. \\
\hline E-H & 9.276 to 12.12 & $<0.0001$ \\
\hline F-H & 9.576 to 12.42 & $<0.0001$ \\
\hline E-G & 9.276 to 12.12 & $<0.0001$ \\
\hline A-B & -5.124 to -2.276 & $<0.0001$ \\
\hline
\end{tabular}

N.S.D. (no significant differences). 
The clinical sensation of the very good stability of the implant was felt at the initial insertion into the polyurethane blocks. No differences were found in the values of the Control A and Control B implants (Tables 1-4). In both these implants, the insertion torque was quite low in the $14.88 \mathrm{kgm}^{3} \mathrm{blocks}(16-28 \mathrm{Ncm})$ (Tables 1 and 2). Better results were found in the $29.76 \mathrm{kgm}^{3}$ blocks, with significantly good stability of the implants. The pull-out values for these control implants were slightly lower than the insertion torque values. High ISQ values were found in both control implants (57-80) (Figure 5; Tables 5 and 6).

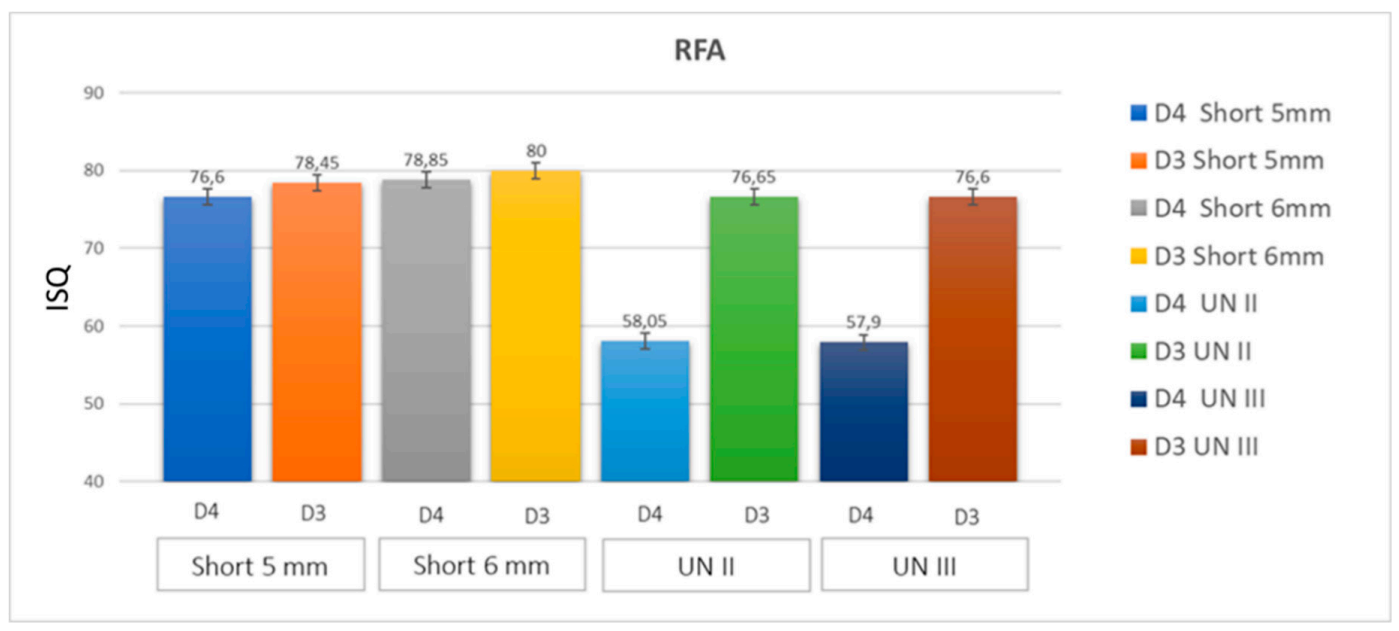

Figure 5. ISQ outcome of the implant positioned into polyurethane foam block: Test A, Test B. Control A and Control B.

Table 5. Summary of the ISQ of the implant positioned into Polyurethane foam (14.88 D4 Density-29.76 kgm ${ }^{3}$ D3 Density); Test A, Test B. Control A and Control B.

\begin{tabular}{cccccccccc}
\hline \multirow{2}{*}{ ISQ } & \multicolumn{4}{c}{ D4 Density } & \multicolumn{5}{c}{ D3 Density } \\
\cline { 2 - 9 } & $\begin{array}{c}\text { Short 5 } \\
\text { mm (A) }\end{array}$ & $\begin{array}{c}\text { Short 6 } \\
\text { mm (B) }\end{array}$ & $\begin{array}{c}\text { UN II } \\
\text { (C) }\end{array}$ & $\begin{array}{c}\text { UN III } \\
\text { (D) }\end{array}$ & $\begin{array}{c}\text { Short 5 } \\
\text { mm (E) }\end{array}$ & $\begin{array}{c}\text { Short 6 } \\
\text { mm (F) }\end{array}$ & $\begin{array}{c}\text { UN II } \\
\text { (G) }\end{array}$ & $\begin{array}{c}\text { UN III } \\
\text { (H) }\end{array}$ \\
\hline Mean & 76.6 & 78.85 & 58.05 & 57.9 & 78.45 & 80 & 76.65 & 76.6 \\
\hline $\begin{array}{c}\text { Std. } \\
\text { Deviation }\end{array}$ & \pm 0.966 & \pm 0.747 & \pm 0.283 & \pm 0.809 & \pm 0.550 & \pm 1.491 & \pm 1.001 & \pm 0.774 \\
\hline
\end{tabular}

Table 6. ISQ: ANOVA Bonferroni Post-hoc comparison test $(\mathrm{CI}=$ Confidence Interval; Diff = Difference).

\begin{tabular}{ccc}
\hline Multiple Comparison RFA & $\mathbf{9 5 . 0 0} \%$ CI of Diff, & Adjusted $p$ Value \\
\hline A-B & -3.430 to -1.070 & $<0.0001$ \\
\hline B-C & 19.62 to 21.98 & $<0.0001$ \\
\hline C-D & -1.030 to 1.330 & N.S.D. \\
\hline A-D & 17.52 to 19.88 & $<0.0001$ \\
\hline B-D & 19.77 to 22.13 & $<0.0001$ \\
\hline A-C & 17.37 to 19.73 & $<0.0001$ \\
\hline D-E & -21.74 to -19.36 & $<0.0001$ \\
\hline E-F & -2.730 to -0.3703 & 0.0027 \\
\hline F-G & 2.170 to 4.530 & $<0.0001$ \\
\hline G-H & -1.130 to 1.230 & N.S.D. \\
\hline E-H & 0.6703 to 3.030 & 0.0002 \\
\hline F-H & 2.220 to 4.580 & $<0.0001$ \\
\hline E-G & 0.6203 to 2.980 & 0.0003 \\
\hline
\end{tabular}

N.S.D. (no significant differences). 


\section{Discussion}

The atrophy of the posterior regions of the jaws with reduced bone quality and quantity could limit the use of standard length implants $(\geq 10 \mathrm{~mm})$, without doing an invasive sinus grafting procedure. Recently, it has been reported in a few systematic reviews with meta-analysis that, in these cases, short implants could be a suitable alternative $[2-8,12,13]$. These reviews have reported, for short implants, survival rates similar to those of standard length implants and the capability to osseointegrate and to bear a functional load [8]. In recent years, a reduction in the implant length of short implants has been reported in the literature $[1,7,8,12]$. Polyurethane foam could be an alternative useful material to provide biomechanical tests substituting, for example, animal bone. ("Standard specification for Rigid Polyurethane Foam for Use as a Standard Material for Test Orthopaedic Devices for Instruments"). Polyurethane presents a cellular structure with constant mechanical characteristics, and similar properties to bone. In the present study, very good stability was obtained for both test and control implants. In the test implants, insertion torque, pull-out torque and ISQ values were all very high, showing the very good stability of both types of SI. Also, all the values for the ST implants were quite high, with better results, and then better stability, in higher density polyurethane blocks. The density of polyurethane blocks is similar to the structure of the bone in the posterior regions in humans. The conical shape of all these implants was probably instrumental in achieving such good levels of stability.

The main reason for measuring the implant primary stability concerns the ability to predict the prognosis of the dental implant procedure. Comuzzi et al., in vitro, reported that in polyurethane foam, ISQ, insertion torque, and pull-out measuring provide the high repeatability and reproducibility that represent suitable indicators for implant stability [26]. In the present investigation, the implant primary stability was evaluated in a controlled reproducible study design and without the variables correlated to the use of animal bone.

The study effectiveness showed that the types of polyurethane used in the present in vitro study were shown to be constituted by a homogenous material.

Moreover, implants with a conical shape have a high stability even in blocks with a low density (D4 Density) and no differences were found between $5 \mathrm{~mm}$ and $6 \mathrm{~mm}$ long implants, where reasonable values of insertion torque and pull-out tests were found in short implants in both polyurethane densities. Comuzzi et al. reported in vitro that a conical shape, rather than a cylindrical design, provided increased values of insertion torque and pull-out strength [26]. Thus, the ISQ values of both short implants were great, with an increased clinical sensation of the high stability of the implants.

The posterior maxilla is an anatomical region often characterized by poor bone quality and quantity. Thus, the $5 \mathrm{~mm}$ short implant could probably be more useful for insertion in this area in cases of reduced bone volume and density.

In fact, the choice of a short implant is clinically indicated as an alternative to more invasive regenerative procedures in cases of bone atrophy of the posterior ridge's regions [3].

The standard length implants had slightly lower values of insertion torque and pull-out torque, and very high ISQ values, where the conometric connection of all the types of implants seemed to also resist quite well to very high torque values (up to $60-80 \mathrm{Ncm}$ ).

\section{Conclusions}

In conclusion, when comparing the SI and ST, the SI had a similar if not better performance in low quality polyurethane foam blocks corresponding to D3 and D4 bone.

Author Contributions: A.P. Conceptualization, L.C. Investigation, A.P., L.C. Methodology; Supervision G.I., Validation A.P., G.I.; M.T. Data Curation, M.T. Formal Analysis; and A.P. and M.T. Writing Original Draft, A.P. and M.T. Writing Review Draft.

Funding: This study was supported by the Italian Ministry of Education, University and Research (M.I.U.R.), Rome, Italy, and by a grant from Implacil De Bortoli, Sao Paulo, Brasil. 
Conflicts of Interest: The authors declare no conflict of interest.

\section{References}

1. Lombardo, G.; Pighi, J.; Marincola, M.; Corrocher, G.; Simancas-Pallares, M.; Nocini, P.F. Cumulative Success Rate of Short and Ultrashort Implants Supporting Single Crowns in the Posterior Maxilla: A 3-Year Retrospective Study. Int. J. Dent. 2017, 2017, 8434281. [CrossRef] [PubMed]

2. Nielsen, H.B.; Schou, S.; Isidor, F.; Christensen, A.E.; Starch-Jensen, T. Short implants ( $\leq 8 \mathrm{~mm})$ compared to standard length implants $(>8 \mathrm{~mm})$ in conjunction with maxillary sinus floor augmentation: A systematic review and meta-analysis. Int. J. Oral Maxillofac. Surg. 2019, 48, 239-249. [CrossRef] [PubMed]

3. Cruz, R.S.; Lemos, C.A.A.; Batista, V.E.S.; Oliveira, H.F.F.E.; Gomes, J.M.L.; Pellizzer, E.P.; Verri, F.R. Short implants versus longer implants with maxillary sinus lift. A systematic review and meta-analysis. Braz. Oral Res. 2018, 32, 86. [CrossRef] [PubMed]

4. Tolentino da Rosa de Souza, P.; Binhame Albini Martini, M.; Reis Azevedo-Alanis, L. Do short implants have similar survival rates compared to standard implants in posterior single crown?: A systematic review and meta-analysis. Clin. Implant. Dent. Relat. Res. 2018, 20, 890-901. [CrossRef] [PubMed]

5. Lemos, C.A.A.; Ferro-Alves, M.L.; Okamoto, R.; Mendonça, M.R.; Pellizzer, E.P. Short dental implants versus standard dental implants placed in the posterior jaws: A systematic review and meta-analysis. J. Dent. 2016, 47, 8-17. [CrossRef] [PubMed]

6. N Dias, F.J.; Pecorari, V.G.A.; Martins, C.B.; Del Fabbro, M.; Casati, M.Z. Short implants versus bone augmentation in combination with standard-length implants in posterior atrophic partially edentulous mandibles: Systematic review and meta-analysis with the Bayesian approach. Int. J. Oral Maxillofac. Surg. 2019, 48, 90-96. [CrossRef]

7. Markose, J.; Eshwar, S.; Srinivas, S.; Jain, V. Clinical outcomes of ultrashort sloping shoulder implant design: A survival analysis. Clin. Implant Dent. Relat. Res. 2018, 20, 646-652. [CrossRef]

8. Urdaneta, R.A.; Daher, S.; Leary, J.; Emanuel, K.M.; Chuang, S.K. The survival of ultrashort locking-taper implants. Int. J. Oral Maxillofac. Implant 2012, 27, 644-654.

9. Ravidà, A.; Barootchi, S.; Askar, H.; Suárez-López Del Amo, F.; Tavelli, L.; Wang, H.L. Long-Term Effectiveness of Extra-Short ( $\leq 6 \mathrm{~mm}$ ) Dental Implants: A Systematic Review. Int. J. Oral Maxillofac. Implant. 2019, 34, 68-84. [CrossRef]

10. Bitaraf, T.; Keshtkar, A.; Rokn, A.R.; Monzavi, A.; Geramy, A.; Hashemi, K. Comparing short dental implant and standard dental implant in terms of marginal bone level changes: A systematic review and meta-analysis of randomized controlled trials. Clin. Implant Dent. Relat. Res. 2019, 21, 796-812. [CrossRef]

11. Deporter, D. Short and Ultrashort Implants; Quintessence Publishing: New Malden, UK, 2018; pp. 59-74.

12. Deporter, D.; Ogiso, B.; Sohn, D.S.; Ruljancich, K.; Pharoah, M. Ultrashort sintered porous-surfaced dental implants used to replace posterior teeth. J. Periodontol. 2008, 79, 1280-1286. [CrossRef] [PubMed]

13. Fan, T.; Li, Y.; Deng, W.W.; Wu, T.; Zhang, W. Short Implants (5 to $8 \mathrm{~mm}$ ) Versus Longer Implants (>8 mm) with Sinus Lifting in Atrophic Posterior Maxilla: A Meta-Analysis of RCTs. Clin. Implant Dent. Relat. Res. 2017, 19, 207-215. [CrossRef] [PubMed]

14. Al-Johany, S.S. Survival Rates of Short Dental Implants $(\leq 6.5 \mathrm{~mm})$ Placed in Posterior Edentulous Ridges and Factors Affecting their Survival after a 12-Month Follow-up Period: A Systematic Review. Int. J. Oral Maxillofac. Implant 2019, 34, 605-621. [CrossRef] [PubMed]

15. Martinolli, M.; Bortolini, S.; Natali, A.; Pereira, L.J.; Castelo, P.M.; Rodrigues Garcia, R.C.M.; Gonçalves, T.M.S.V. Long-term survival analysis of standard-length and short implants with multifunctional abutments. J. Oral Rehabil. 2019, 46, 640-646. [CrossRef]

16. Felice, P.; Soardi, E.; Pellegrino, G.; Pistilli, R.; Marchetti, C.; Gessaroli, M.; Esposito, M. Treatment of the atrophic edentulous maxilla: Short implants versus bone augmentation for placing longer implants. Five-month post-loading results of a pilot randomised controlled trial. Eur. J. Oral Implant 2011, 4, 191-202.

17. Gehrke, S.A.; Guirado, J.L.C.; Bettach, R.; Fabbro, M.D.; Martínez, C.P.A.; Shibli, J.A. Evaluation of the insertion torque, implant stability quotient and drilled hole quality for different drill design: An in vitro Investigation. Clin. Oral Implant Res. 2018, 29, 656-662. [CrossRef] 
18. Romanos, G.E.; Delgado-Ruiz, R.A.; Sacks, D.; Calvo-Guirado, J.L. Influence of the implant diameter and bone quality on the primary stability of porous tantalum trabecular metal dental implants: An in vitro biomechanical study. Clin. Oral Implant Res. 2018, 29, 649-655. [CrossRef]

19. Möhlhenrich, S.C.; Heussen, N.; Elvers, D.; Steiner, T.; Hölzle, F.; Modabber, A. Compensating for poor primary implant stability in different bone densities by varying implant geometry: A laboratory study. Int. J. Oral. Maxillofac. Surg. 2015, 44, 1514-1520. [CrossRef]

20. Yamaguchi, Y.; Shiota, M.; FuJii, M.; Sekiya, M.; Ozeki, M. Development and application of a direct method to observe the implant/bone interface using simulated bone. Springerplus 2016, 5, 494. [CrossRef]

21. Falco, A.; Berardini, M.; Trisi, P. Correlation Between Implant Geometry, Implant Surface, Insertion Torque, and Primary Stability: In Vitro Biomechanical Analysis. Int. J. Oral Maxillofac. Implant 2018, 33, 824-830. [CrossRef]

22. Di Stefano, D.A.; Arosio, P.; Gastaldi, G.; Gherlone, E. The insertion torque-depth curve integral as a measure of implant primary stability: An in vitro study on polyurethane foam blocks. J. Prosthet. Dent. 2018, 120, 706-714. [CrossRef] [PubMed]

23. Tsolaki, I.N.; Tonsekar, P.P.; Najafi, B.; Drew, H.J.; Sullivan, A.J.; Petrov, S.D. Comparison of Osteotome and Conventional Drilling Techniques for Primary Implant Stability: An In Vitro Study. J. Oral Implant 2016, 42, 321-325. [CrossRef] [PubMed]

24. Oliveira, P.S.; Rodrigues, J.A.; Shibli, J.A.; Piattelli, A.; Iezzi, G.; Perrotti, V. Influence of osteoporosis on the osteocyte density of human mandibular bone samples: A controlled histological human study. Clin. Oral Implant Res. 2016, 27, 325-328. [CrossRef] [PubMed]

25. Sennerby, L.; Meredith, N. Implant stability measurements using resonance frequency analysis: Biological and biomechanical aspects and clinical implications. Periodontology 2008, 47, 51-66. [CrossRef]

26. Comuzzi, L.; Iezzi, G.; Piattelli, A.; Tumedei, M. An In Vitro Evaluation, on Polyurethane Foam Sheets, of the Insertion Torque (IT) Values, Pull-Out Torque Values, and Resonance Frequency Analysis (RFA) of NanoShort Dental Implants. Polymer 2019, 11, 1020. [CrossRef]

(C) 2019 by the authors. Licensee MDPI, Basel, Switzerland. This article is an open access article distributed under the terms and conditions of the Creative Commons Attribution (CC BY) license (http://creativecommons.org/licenses/by/4.0/). 